This item was submitted to Loughborough's Research Repository by the author.

Items in Figshare are protected by copyright, with all rights reserved, unless otherwise indicated.

\title{
Design of a semi-autonomous modular robotic vehicle for gas pipeline inspection
}

PLEASE CITE THE PUBLISHED VERSION

PUBLISHER

Professional Engineering Publishing / @ IMECHE

VERSION

VoR (Version of Record)

LICENCE

CC BY-NC-ND 4.0

\section{REPOSITORY RECORD}

Ong, J.K., David Kerr, and Kaddour Bouazza-Marouf. 2019. "Design of a Semi-autonomous Modular Robotic Vehicle for Gas Pipeline Inspection". figshare. https://hdl.handle.net/2134/5145. 
This item was submitted to Loughborough's Institutional Repository (https://dspace.lboro.ac.uk/) by the author and is made available under the following Creative Commons Licence conditions.

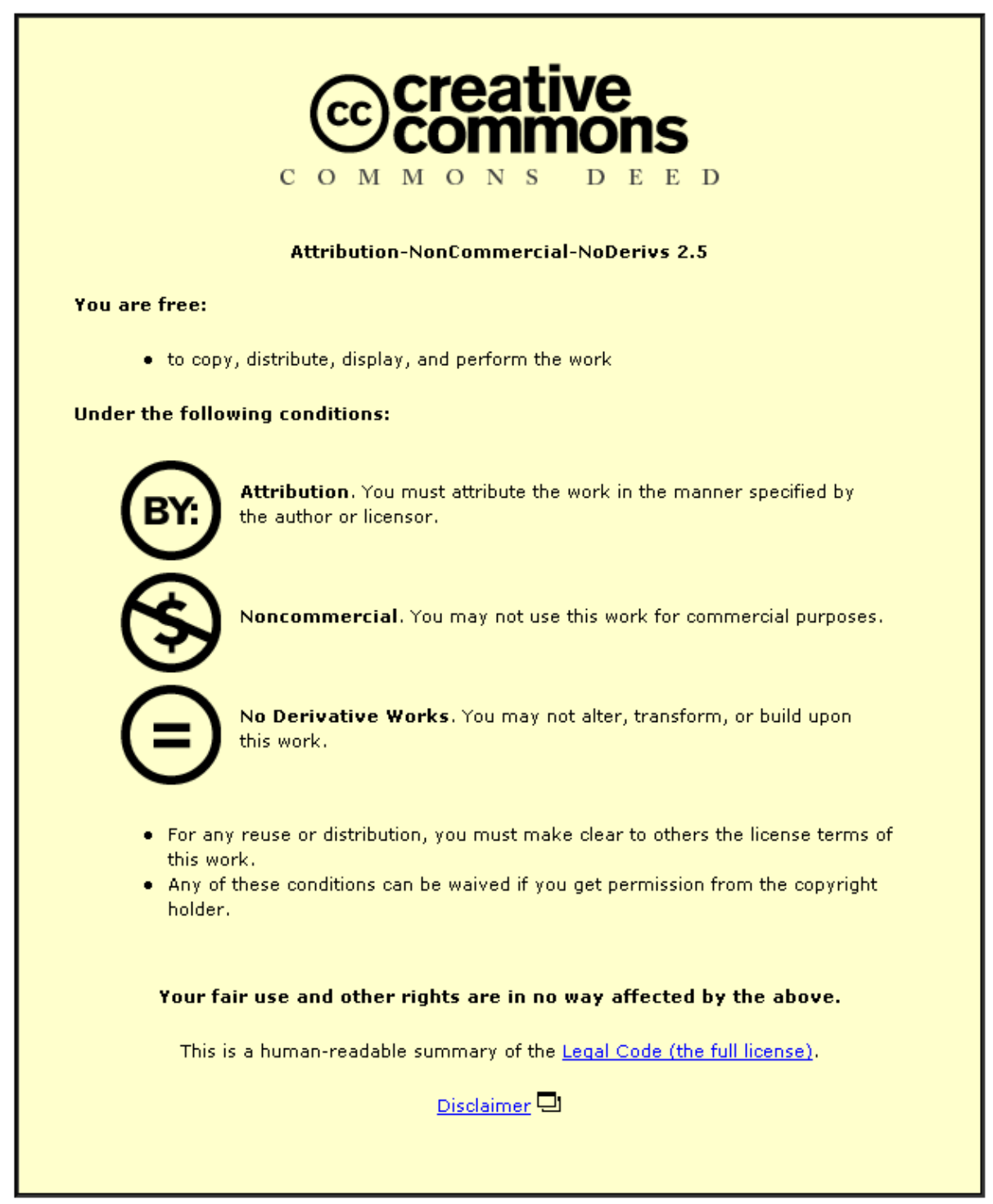

For the full text of this licence, please go to: http://creativecommons.org/licenses/by-nc-nd/2.5/ 


\title{
Design of a semi-autonomous modular robotic vehicle for gas pipeline inspection
}

\author{
J K Ong*, D Kerr and K Bouazza-Marouf \\ Wolfson School of Mechanical and Manufacturing Engineering, Loughborough University, Loughborough, \\ Leicestershire, UK
}

\begin{abstract}
This paper presents a new solution for inspecting and repairing defects in live gas pipelines. The proposed approach is the development of a modular and semi-autonomous vehicle system. The robotic system has a drive mechanism, capable of navigating and adjusting its orientation in various configurations of pipelines. Other features of the system are cable-free communications, semiautonomous motion control as well as integration of sensory devices. The robotic system is designed to traverse in $150-300 \mathrm{~mm}$ diameter pipes through straight and curved sections, junctions and reducers. The vehicle control and navigation technique is implemented using a two-mode controller consisting of a proportional-integral-derivative (PID) and fuzzy logic control. Unlike other available systems, the vehicle employs proprioceptive sensors to monitor its own states. The fuzzy logic controller is used to evaluate the sensor outputs such as speed, climbing angle and rate of change of climbing angle. This control technique allows the vehicle to drive and adapt in a partially observable gas pipe system. Laboratory experiment results are presented. The paper also describes a cable-free communication method for the system. A brief account of typical pipe environments and currently available inspection tools is presented as background information.
\end{abstract}

Keywords: gas pipe inspection tool, mobile robotic system, navigation control in gas pipes, fuzzy logic controller, cable-less communication in gas pipes

\section{NOTATION}

$A$

$A_{\mathrm{e}}$

$d$

$D_{\mathrm{v}}$

$D_{\mathrm{p}}$

$L$

$L_{\mathrm{b}}$

$L_{\mathrm{T}}$

$R$

$\Delta S_{\mathrm{L}}$

$\Delta S_{\mathrm{R}}$

$U$

$V_{\mathrm{L}}$

$V_{\mathrm{R}}$

$\alpha$

$\beta$ projected pipe area between wheels

projected beam area at distance $L_{\mathrm{T}}$

distance between wheels

diameter of vehicle unit

nominal diameter of pipe

length of vehicle unit

distance between front and rear wheels

transmission distance

radius of curvature of bend

left wheel travel distance

right wheel travel distance

forward velocity

left side velocity

right side velocity

turning angle in bend

wheel position angle on the chassis

The MS was received on 13 August 2002 and was accepted after revision for publication on 4 December 2002.

* Corresponding author: Wolfson School of Mechanical and Manufacturing Engineering, Loughborough University, Loughborough, Leicestershire LE11 1QG, UK.

$\theta \quad$ climbing angle

$\theta_{\mathrm{D}} \quad$ beam divergence angle

\section{INTRODUCTION}

The need for devices for gas pipeline inspection and servicing has increased in demand recently. Many underground gas pipelines laid decades ago have deteriorated over time due to internal corrosion, ground movement, misalignment, etc. Pipe leakages, surface cracks and deterioration are unacceptable both commercially and on safety and environmental grounds. Frequent inspections and servicing are therefore needed.

Inspection and maintenance work on underground gas pipes is normally accompanied by ground excavations and replacement of significant lengths of pipes. The operation is both costly and time consuming. For 'noninspectable' pipe sections, such as small diameter, complicated structures and restricted access, the operators have to rely on statistical data analysis to gain knowledge of pipe conditions [1, 2]. Added cost and labour are incurred in such 'guess and replace' maintenance work $[3,4]$.

Proc. Instn Mech. Engrs Vol. 217 Part I: J. Systems and Control Engineering 
This paper attempts to address the needs of reformation of in-pipe maintenance and inspection tools. Various types of tools in current use or developed recently do not provide sufficient services for the given pipe environment. A promising approach is to have a mechatronic system or intelligent tool to offer greater flexibility and versatility [5].

The approach described here is a multirobotic vehicular system, built to achieve modular and self-navigation abilities. The various stages and progression of the research work are described. These include a self-driven propulsion mechanism design, a cable-less communication capability and a robust navigation method to establish a semi-autonomous system for pipelines.

A review of currently available systems and tools is provided in section 2 . The most traditional and widely used method of inspection has been by deploying 'intelligent' or 'smart' passive devices (pigs) into the pipe, driven by the pipeline product flow. Other inspection tools have included camera probes and robotic systems. However, the applications of these inspection devices have certain limitations due to pipeline configurations and restrictive components, such as bends and valves $[6,7]$. The research work described in this paper is based on a critical evaluation of the above review. This is described in section 3, while section 4 outlines the system design overview. Section 5 describes the control scheme developed to provide a robust navigation inside gas pipelines. A navigation control algorithm is necessary to perform the desired motion and orientation control in an unknown pipeline environment. A proportionalintegral-derivative (PID) control structure complemented with fuzzy logic is used. Initially, the input variables are processed through the fuzzy logic operators and linked, via a set of linguistic rules, to the fuzzy output during the composition and encoding stages. The fuzzy output is then 'defuzzified' to produce a crisp output value [8]. Section 6 summarizes the experimental results of the robotic vehicle unit in terms of its control and mobility in pipelines.

A cable-free communication method is proposed for the new system, as the review showed that operational distance is limited due to umbilical cable drag and friction. This feature and related experiments are presented in section 7.

\section{THE PIPELINE AND ITS MAINTENANCE TOOLS}

\subsection{Gas pipeline environment}

Advancement of technology in material science, geology and appreciation in gas flow modelling have allowed great improvements in pipeline construction. Elaborate layouts are being constructed using more durable materials and improved fittings. Nonetheless, many mainten- ance tools incur added difficulties due to pipeline location, complex configuration, inconsistent characteristics, etc. Pipelines are often composed of a range of materials, such as steel, cast iron and polyethylene (PE). Fittings such as elbows, reducers and branches are used to deliver gas to a wider area.

There are currently three major gas pipeline systems within the United Kingdom [6]. The High Pressure Transmission Grid or National Transmission System (NTS) connects an offshore terminal to the Local Transmission Zone (LTZ). The LTZ consists of Local Transmission Systems (LTS) and Local Distribution Systems (LDS). The LDS are further split into three pressure tiers: intermediate pressure (2-7 bar), medium pressure $(75 \mathrm{mbar}-2 \mathrm{bar})$ and low pressure (19-75 mbar).

Most of the LDS pipelines are located in city areas or underneath roads. They are operated at low pressure and are of small diameter ranging from 100 to $355 \mathrm{~mm}$. LDS, different from NTS or LTS, have complicated configurations and may exhibit a wide range of defects.

\subsection{Available tools}

Various working tools are available for in-pipe operations. The type of inspection tools selected for operational use is interdependent on pipe configurations and conditions as well as the characteristics of the tools. Types of in-pipe tools can be categorized into three groups:

(a) those that utilize transported fluid pressure in the pipeline for propulsion (pigging tools);

(b) those that push a TV camera via a flexible rod such as the Flexi-Probe camera, or borescopic tools;

(c) those that have an integrated drive mechanism (mobile systems).

Development of pipe 'pigs' is well established. Pig inspection operations are usually limited to relatively straight and uninterrupted length pipes operating in the high-pressure range. This is due to the pig's rigidity, lack of self-propulsion and steering ability. Moreover, these devices are bulky and not portable. The other category of inspection-only tools is typified by the pushrod camera [9]. Their performance is limited by several factors such as cable friction and drag-around turns, pushing speed, low camera resolution, etc. Cable friction shortens the operational distance and subsequently many excavations are required.

The third type of inspection tool, represented by various evolutions of robotic systems, has received extensive attention recently [10-12]. Significant effort has been put into devising an effective mechanism to drive the robotic systems through different pipe configurations. Many variations of drive mechanisms such as wheels, crawlers, inchworm and pushrods have been investigated 
by academic researchers and commercial companies. Some systems have complex mechanisms and linkages, which in turn require complicated actuation and control. Wheeled systems claimed the edge over the majority due to their relative simplicity and ease of navigation and control [7]. Comparatively, they are able to travel relatively fast and far. Among the common configurations are three-wheeled vehicles and multimodule, train-like mobile systems.

The capabilities of current servicing tools, such as pigs, are limited to inspection and water or dirt purging. Other types have only inspection ability. Pipe repairing and maintenance are mostly done externally after detecting the defects, by either replacing the pipe section or relining the pipe internally. It is generally believed that a robotic system, properly equipped and controlled, is capable of carrying out more delicate maintenance tasks such as sealing leaks and cracks and analysing flow materials. Current mobile robotic systems are not yet adequately equipped for such tasks in a complex pipe environment.

The current challenges of developing a robotic system for use in gas pipelines are to develop an effective driving mechanism, with an appropriate control strategy, and to design an optimal payload configuration for the proposed maintenance tasks.

\section{OVERVIEW OF THE PROPOSED SYSTEM}

At present, there is no entirely successful generic mechanism available for mobility inside gas pipes. Also, there has been (to the authors' knowledge) no mention in the literature of any untethered and autonomous mobile robotic systems. In their opinion, these capabilities would offer great advantages. This lack of autonomy may be due more to the environment and tasks involved, rather than control and software limitations.

A new type of gas pipe servicing system concept is proposed in this paper. The focus of the work has not been the development of an all-purpose mobility; rather it is based on a mechatronic approach, deliberately taking advantage of robotic technologies and intelligent control to develop a semi-autonomous, moderately selfadaptable robotic system. The research work has also focused on building a system to introduce the aforementioned lacking features of existing devices, in addition to their principal functionalities.

A few stages have been identified for the development of the proposed system. Apart from an efficient and modular mechanism to enable movement in the pipe environment, a robust controller and an appropriate autonomy level are needed [13]. The robotic vehicle should be able to readjust its parameters, such as speed, orientation and torque, according to environmental changes to ensure robust performance. A navigation technique is also required for moving around difficult fittings and obstacles.

One of the main interests of this research was to establish a robotic system with cooperative ability. Such an idea is envisioned due to the complexity of the pipe environment as well as the variation of tasks that require a mix of robotic capabilities that is too expensive to design into a single machine. Multivehicles also have reconfigurable, modularity and expandable advantages that enable task distribution by means of addition of more mobile units or different tools. In the future, routine inspection tasks will start to attract less interest than maintenance as the pipeline network ages but at the same time expands rapidly. Pipe operators are in need of a more automated and versatile tool to allow cost and time-saving maintenance work to be carried out.

A communication system is needed for the multirobotic vehicle systems to acknowledge the presence of other vehicles and the tasks in which they are engaged [13]. The robotic modules then have the ability to give or receive implicit environment models or actions of other modules. In order to achieve this, a cable-less option has been chosen. The cable-less communication method proposed here will prove a challenging task. Not only has cable been routinely used for communication, it is also a means of supplying power and can act as a tracking and rescue device. On the other hand, not having cable means greater operational distances and no handling complications. The robotic system overcomes the need for cable for power supply and communication, by carrying sufficient rechargeable battery packs and a high bandwidth device for video and data transmission.

\section{THE ROBOTIC VEHICLE MODULE}

A mechatronic system design approach has been adopted in this research. This approach allows for a lesscomplicated driving mechanism to be used. The target pipe network is the LDS, where gas pipeline operators are still relying on a statistical approach to determine the servicing operation.

\subsection{Vehicle design}

The vehicle design will have to fulfil the following LDS pipelines requirements: (a) available for 150-300 mm nominal pipe diameters, (b) a minimum $600 \mathrm{~m}$ of operation distance (cable-less communication) with a speed faster than $3 \mathrm{~cm} / \mathrm{s}$, (c) the ability to overcome bends (with a curvature larger than 1.5 times the nominal diameter), reducers and diameter changes, (d) the ability to recognize common pipe fittings, thus enabling self-navigation, (e) the ability to carry necessary sensors and tools. One major concern is the vehicle's 
manoeuvrability in highly constrained pipe space with various fittings. Among the fittings, the right-angle bends pose a great difficulty as they may trap the vehicle in the curvature. This geometrical constraint has been modelled and is shown in Fig. 1. The allowable length and width are obtained according to the following equations to allow smooth steering through bends:

$$
\begin{aligned}
& 0<D_{\mathrm{v}}<\left(R+\frac{1}{2} D_{\mathrm{p}}\right) \cos \alpha-\left(R-\frac{1}{2} D_{\mathrm{p}}\right) \\
& L<2\left[\left(R+\frac{1}{2} D_{\mathrm{p}}\right)^{2}-\left(D_{\mathrm{v}}+R-\frac{1}{2} D_{\mathrm{p}}\right)^{2}\right]^{1 / 2} \\
& \text { Volume }=\pi\left(\frac{1}{2} D_{\mathrm{v}}\right)^{2} L
\end{aligned}
$$

The proposed unit is a four-wheeled vehicle driven by two d.c. motors, one for each side. The prototype vehicle is shown in Fig 2. The vehicle dimensions are $152 \mathrm{~mm}$ in length and $114 \mathrm{~mm}$ in diameter [14]. The wheels are positioned at $\beta=55^{\circ}$ from the horizontal at each side of the cylindrical chassis, as shown in Fig. 3, to maximize surface contact with the pipe wall as the vehicle moves through multidiameter pipes, such as from 150 to $200 \mathrm{~mm}$. The above $\beta$ angle has been chosen to prevent the wheels from falling into smaller lateral openings, such as take-offs to service pipes and to ensure stability against rolling and tumbling. The wheels also provide $15 \mathrm{~mm}$ obstacle clearance to allow the vehicle to move over protrusions and accumulations of dirt and water.

The two drive motors are controlled separately and are connected to the front wheels using a set of worm gearings and a timing belt. The rear wheels are driven by the front wheels using timing belts. Any difference in speed between the left and right set of wheels will result in the vehicle climbing the pipe. This, however, is necessary for manoeuvring the vehicle in straight pipes and negotiating bends. Thus, by varying the speed ratio, the vehicle can negotiate a range of bend angles. The minimum bend radius that the vehicle can negotiate is one

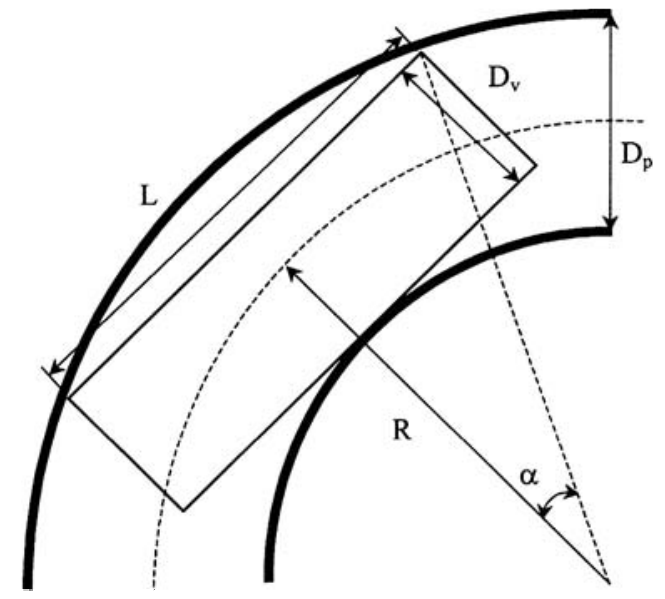

Fig. 1 Constraints on vehicle dimensions

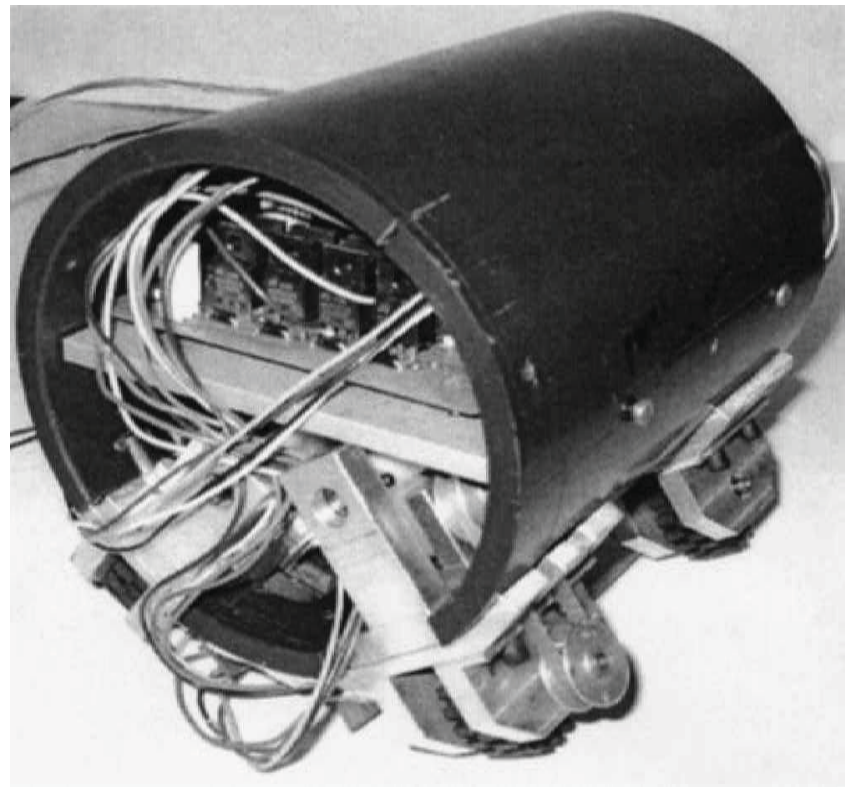

Fig. 2 The prototype robotic vehicle unit

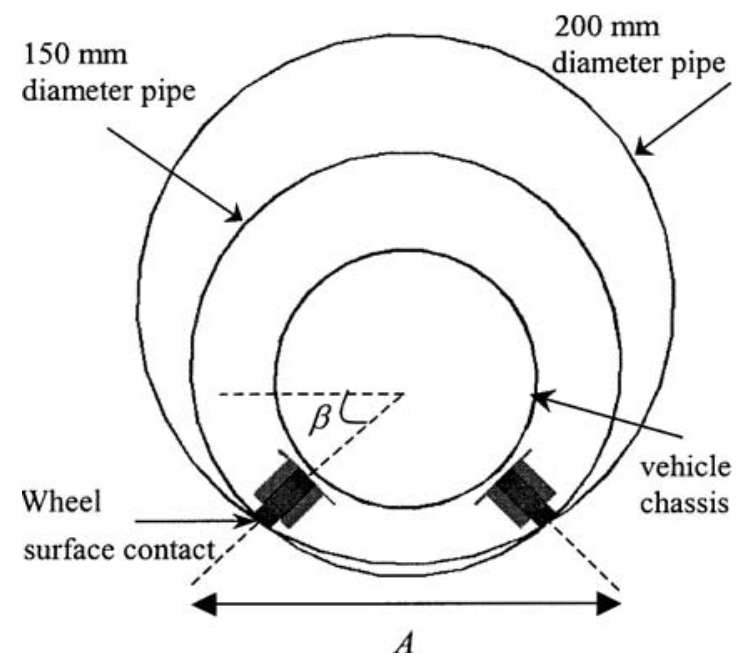

Fig. 3 Vehicle in pipe schematic

and a half times the nominal pipe diameter, due to the selected vehicle dimensions and the space constraints in bends. Figure 4 as well as the following equations show that speed ratio navigation is necessary in bend sections since the distance travelled by the outer wheels is larger than the inner wheels:

$$
\begin{aligned}
& \Delta S_{\mathrm{L}}=\left(R+\frac{d}{2}\right) \Delta \alpha \\
& \Delta S_{\mathrm{R}}=\left(R-\frac{d}{2}\right) \Delta \alpha
\end{aligned}
$$

\subsection{Sensors selection}

The robotic vehicle employs proprioceptive sensors, which monitor the state of its own body, to provide the 


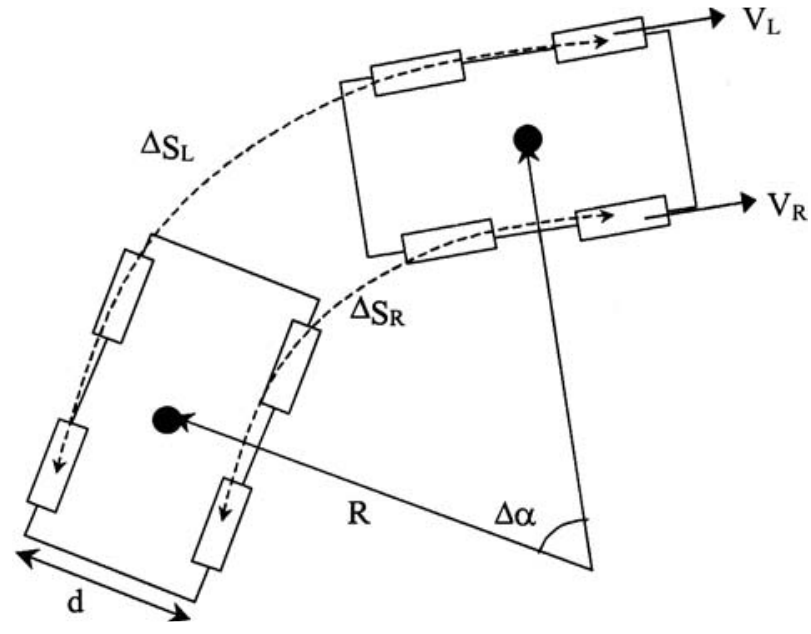

Fig. 4 Difference in wheels travel distance due to bend

feedback information that represents the current status of the robotic vehicle and the pipe environment. The sensors used are reflective infrared encoders and a tilt sensor. While it is tempting to choose the single mostappropriate sensor and rely on its output alone, sensory data from all applicable sensors can be combined to generate a composite view. The vehicle system is then able to sense environmental factors from using these multiple information sources and to adjust its navigation behaviour accordingly. The sensor information interpretation task is carried out by a fuzzy logic inference system, which is discussed in section 5.2.

An infrared encoder is attached to each side of the wheel assemblies to measure rotational speed. Optical encoders provide good accuracy, allow high sampling rates and are inexpensive, light and compact. However, counting the number of encoder pulses over time and computing the time rate of change of the values to measure speed may lead to errors. Some measures have been taken to overcome these errors; e.g. a low-pass filter is used in the speed measurement feedback and a fuzzy logic algorithm is used in the fusion of vehicle speed data and tilt measurement to quantitatively reduce measurement uncertainty and therefore obtain more reliable vehicle actions and pipe environment estimations.

The second type of sensor used is for measuring the climb angle of the robotic vehicle. Such measurements could be obtained using accelerometers or tilt sensors. Accelerometers are not suitable since the vehicle angle is estimated by double integration of angular acceleration. This causes a large drift in angle measurement if this sensor is used for an extended time [15]. A common tilt sensor is one based on the principle of the spirit level, in which the sensor itself consists of a curved tube containing an electrically conducting liquid and three electrodes. This sensor was not chosen for this application since an a.c. power supply is needed and it is more fragile. Instead, a tilt sensor, which uses a ceramic substrate that contains a thick-film deposited platinum circuit, is used. The sensor offers a subarc second resolution $\left(0.001^{\circ}\right)$, good null stability and a wider measuring range $\left( \pm 60^{\circ}\right)$. The sensor is attached vertically in front of the robotic vehicle.

Effectively, the complementary measurement and post-processing of the speed and tilt angle are sufficient for the control algorithm to successfully navigate the robotic vehicle through common pipe fittings.

\section{NAVIGATION CONTROLLER}

There are three recognized problems in motion control of mobile robotic vehicles in pipelines [6]. Firstly, the underground pipeline environment is not completely known. Secondly, this environment is only partially observable. Finally, the action of the robotic system may not be executed correctly. These problems can be minimized by using an appropriate control technique and sensory feedback. However, the sensor feedback may be ambiguous or noisy and may not be correctly interpretable for the control system to derive decisions and actions.

It should be noted that the development of this robotic system is not categorized in a novel mechanism domain, and thus an intelligent control technique is necessary to enhance its performance. The development of the controller for the robotic vehicle can be divided into three parts: the speed control, climbing angle control and pipe fittings recognition. Two principles have been adopted at the outset:

1. The pipe fittings recognition algorithm should always be active but should not affect the normal operation of the vehicle navigation controller.

2. Any demand on speed and climbing angle input by the operator should be met.

The first principle requires high-level navigation control and pipe fittings recognition to be integrated to prevent conflicts. The second principle can be achieved by a PID control system. Therefore, as a requirement, the control architecture should support parallel execution of several low-level program processes (e.g. sensor sampling or communication) and high-level tasks (e.g. navigation or optimization of performance).

\subsection{PID controller}

A PID controller is implemented on-board the vehicle for motion control, i.e. for speed and climbing angle control of the vehicle. The states of the vehicle are described in terms of right and left speed $\left(V_{\mathrm{R}}, V_{\mathrm{L}}\right)$ and climbing angle $(\theta)$. Basic movements include forward, reverse, braking and climbing left or right. The simplified model of the control scheme is as shown in Fig. 5. A microcontroller board (using PIC16F876) was designed 


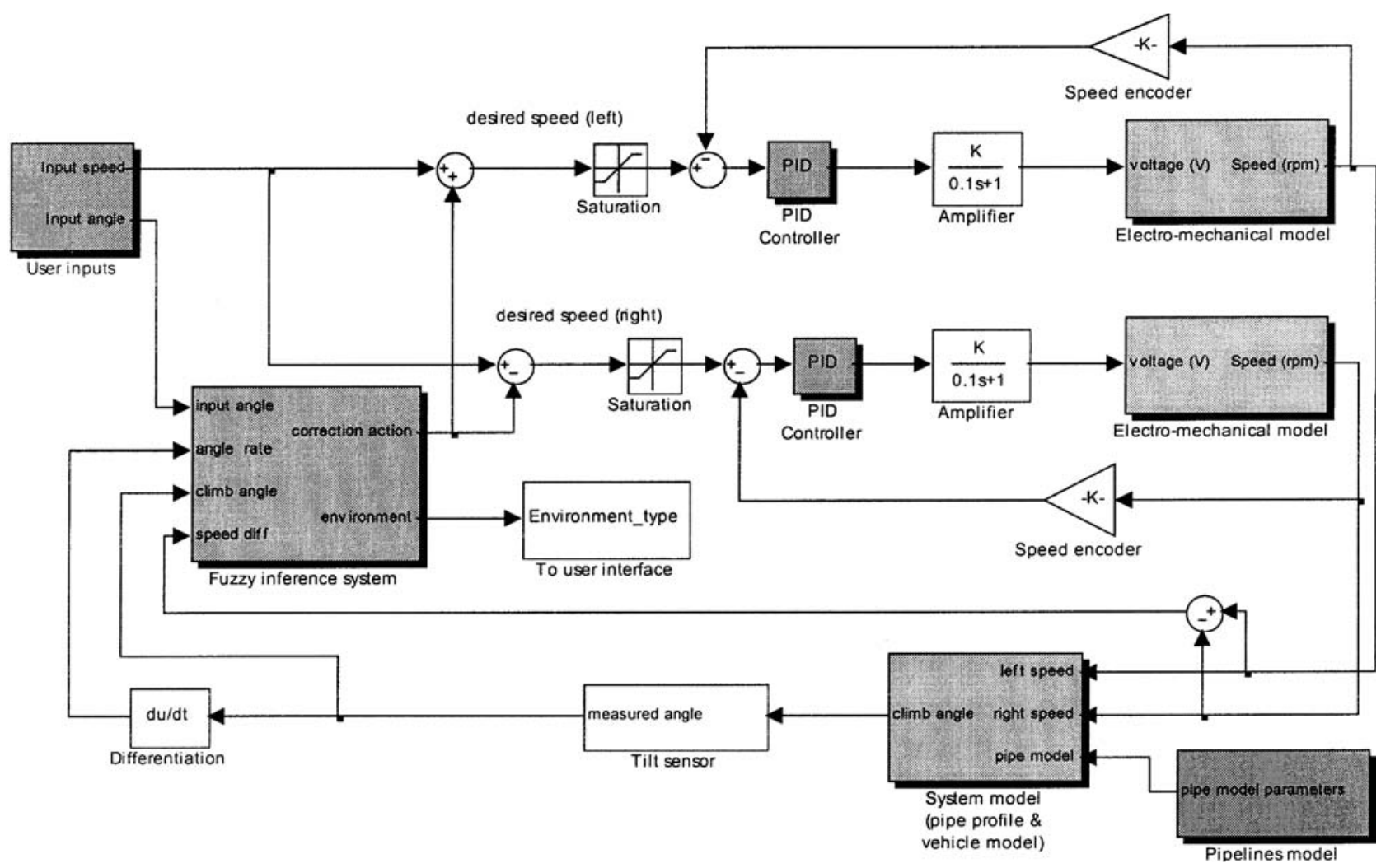

Fig. 5 Control and navigation algorithm of the robotic vehicle

and used to implement the control algorithm. In the first part of the algorithm, the speed and angle inputs are computed to produce the desired speed for each drive. In the second part, the PID control algorithm is executed. The advantages of a PID control configuration are its simplicity and effectiveness in achieving the desired motion of the vehicle. A sampling time, $T$, of $0.05 \mathrm{~s}$ was used in the digital implementation of the PID controller. The value of $T$ was selected based on the settling time of the tilt sensor. In operation, the sensory data are continously fed into the on-board microcontroller and transmitted via a communication link to the operator's workstation.

In addition to the on-board PID controller, there is a need to control the vehicle velocity in order to be able to achieve rapid changes in climbing angle when necessary, particularly when encountering obstacles such as pipe junctions and tight turns. This is achieved using a fuzzy logic navigation controller.

\subsection{Fuzzy logic navigation controller}

A high-level controller will allow the robotic vehicle to self-navigate in the pipe configurations without extensive operator intervention. Fuzzy logic is chosen to perform different levels of abstraction and interpretation of sensor information because of its ability to handle vagueness and uncertainty of the environment and dynamic model of the system [16]. This controller is included in the overall control loop to measure drift, recognize the type of pipe bends and fittings, and adjust the speed as necessary. Correction is achieved by adjusting the driving speed at each side to maintain position, restrict climbing angle or allow climbing. The fuzzy controller is developed in such a way that it only requires two types of sensory inputs, the vehicle tilt angle and speed, to govern the vehicle behaviour.

Due to the bend angle and three-dimensional circular surface of bends, which have a larger travel distance at the outer diameter than at the inner one, the vehicle naturally tends to move outwards and upwards when turning. Therefore, there exists an observable and distinct rate of climbing angle change between the vehicle drifting and moving in a bend. By coupling this rate of climbing angle with measured speed and angle, the angular rate of change can be used to recognize the various types of bends.

The Takagi-Sugeno [17] fuzzy rules inference system is used to achieve this recognition, where 36 rules have been formulated. Three of these are given below and are used to recognize drift, bends and exiting a bend:

1. If angle is small, and angle rate is very small, then action is drifting.

2. If speed is small, and angle is moderate, and angle rate is moderate, then action is turning and environment is $60 \mathrm{deg}$ bend. 


\section{If speed is moderate, and angle rate is negatively} moderate, then action is exiting bend.

Example rule 1 allows the controller to maintain the vehicle's orientation, whereas rule 2 will allow the controller to recognize the environment and control the vehicle to follow the curvature of bends. Example rule 3 prepares the vehicle to correct its orientation to its original position as it exits the bend. Figure 6 shows the interaction of the input variables via the set of rules to produce the required vehicle behaviour for various types of bends. All rules are evaluated in parallel. The adjectives such as 'small', 'moderate' and 'drifting' correspond to a curve that defines the degree or range of the vehicle's behaviour. The membership functions of the input variables are as shown in Figs 7a, b, c and d. The inputs are symmetrical about zero; thus only the positive sets are shown. The angle rate diagram in Fig. 7c shows a narrowing range at near zero, allowing many types of bends to be recognized. The output membership functions are linear or constant for the Sugeno-type fuzzy system. For example, the environment output membership function of ' 60 deg bend' would be a singleton spike of value 2 . The user interface is programmed to match the fuzzy output to the environment types.

The decision-making fuzzy controller was designed and compiled using MATLAB and incorporated into the user interface implemented in the user workstation. This was necessary as it is not possible to implement the fuzzy controller algorithm on the on-board microcontroller due to its limited processing ability.

The application of the fuzzy controller allowed the robotic vehicle to navigate itself by obtaining just sufficient feedback from the environment and utilizing the information efficiently. The performance of the vehicle unit is described in the following section.

\section{EVALUATION OF THE ROBOTIC SYSTEM}

The evaluation of the robotic vehicle system structure is based on the following functionalities:

(a) the manoeuvrability and movement in the pipe environment,

(b) navigation and control,

(c) the load capacity.

A pipe arrangement as shown in Fig. 8 has been used to evaluate the performance of the robotic vehicle system. Polyethylene (PE) gas pipes were used and consisted of a reducer, an elbow and a $\mathrm{T}$-junction. The pipe diameters were 150 and $200 \mathrm{~mm}$. The arrangement covers some possible configurations in a local transmission system that are most frequently encountered for a typical oneoff inspection.

The driving torque of the vehicle is $780 \mathrm{mN}$ m and the maximum speed is approximately $25 \mathrm{~cm} / \mathrm{s}$. The desired speed and angular position are used by the controller to set the rotational speed for each motor by adjusting the respective pulse width modulation (PWM) duty cycle. The vehicle was tested extensively in the 150 and $200 \mathrm{~mm}$ diameter straight pipes and a $90^{\circ}$ bend section. For example, Fig. 9 demonstrates the vehicle's ability to move and climb up to a desired angle in a straight pipe,

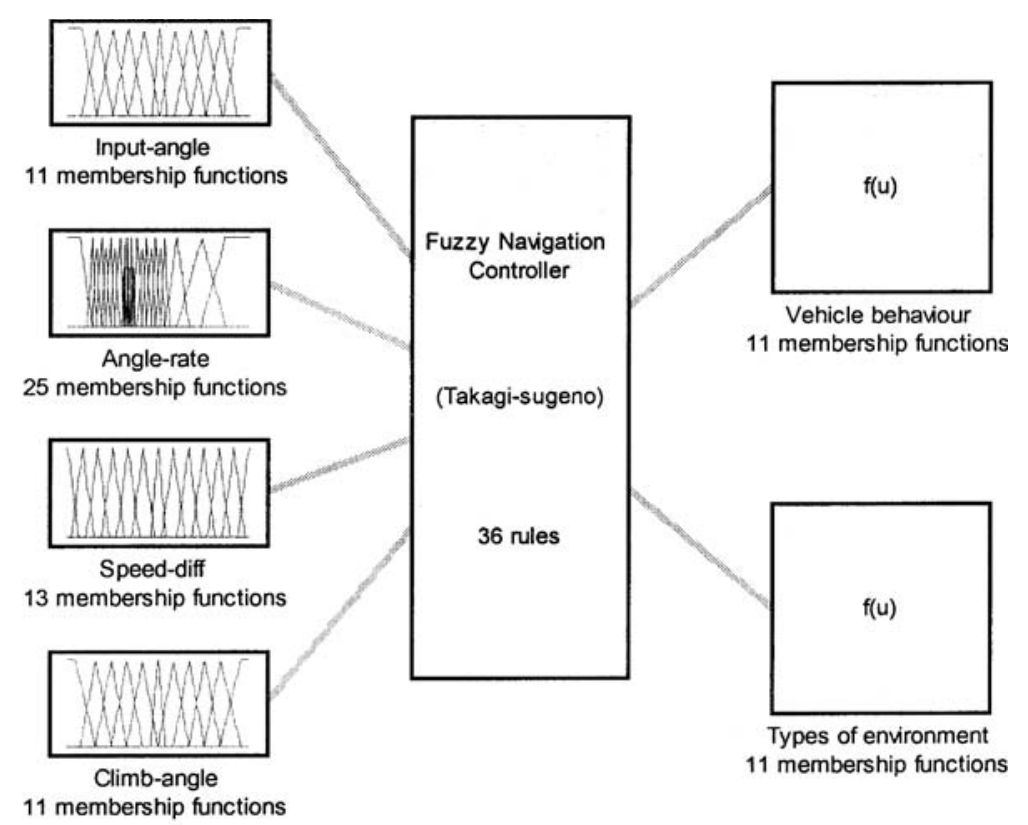

System Fuzzy Navigation Controlleri: 4 inputs, 2 outputs, 36 rules

Fig. 6 Fuzzy inference system for vehicle navigation control 


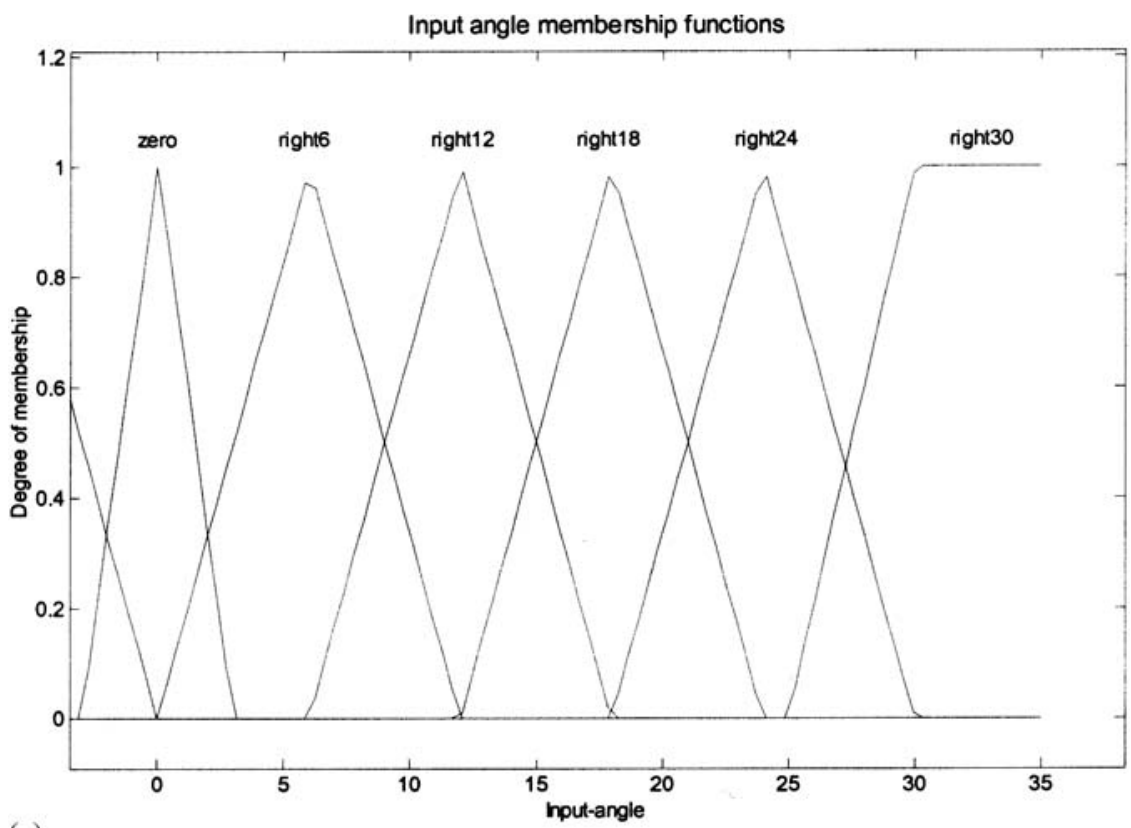

(a)

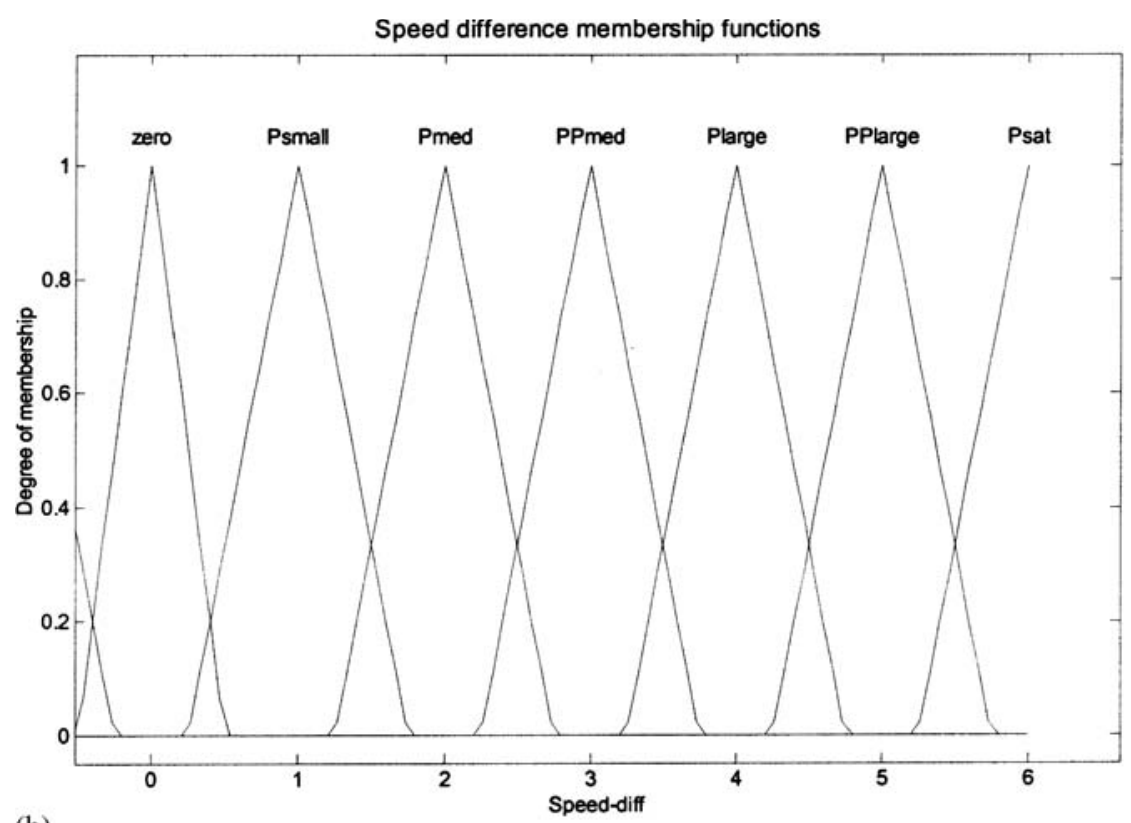

(b)

Fig. 7 (continued over)

Fig. 10 shows the vehicle entering a $90^{\circ}$ bend section from the zero angle position and Fig. 11 shows the vehicle in the middle of the bend section. It should be noted that in Fig. 11 the vehicle has climbed an angle towards the outer surface to enable it to move through the $90^{\circ}$ turn. The experiments have shown that the vehicle has satisfactory mobility and has been able to navigate successfully within the pipeline set-up. These laboratory tests have verified that the robotic system is able to cope with the following configurations:

(a) curves and bends, reducers, inclined pipes (up to $15^{\circ}$ incline angle);

Proc. Instn Mech. Engrs Vol. 217 Part I: J. Systems and Control Engineering (b) smaller size junctions $(50-100 \mathrm{~mm})$ along the inspected pipes;

(c) uneven or defective surfaces, deposits, dust, etc.

The vehicle was able to go through the T-junction. However, turning at the T-junction has not been implemented because turning at T-junctions is seldom encountered in practice for LDS networks. Turning at T-junctions would require a complex vehicle configuration, which is not the purpose of this research. Due to its simple drive assembly, the developed vehicle would lose surface contact on one pair of wheels at some point during the turn in a $\mathrm{T}$-junction. 


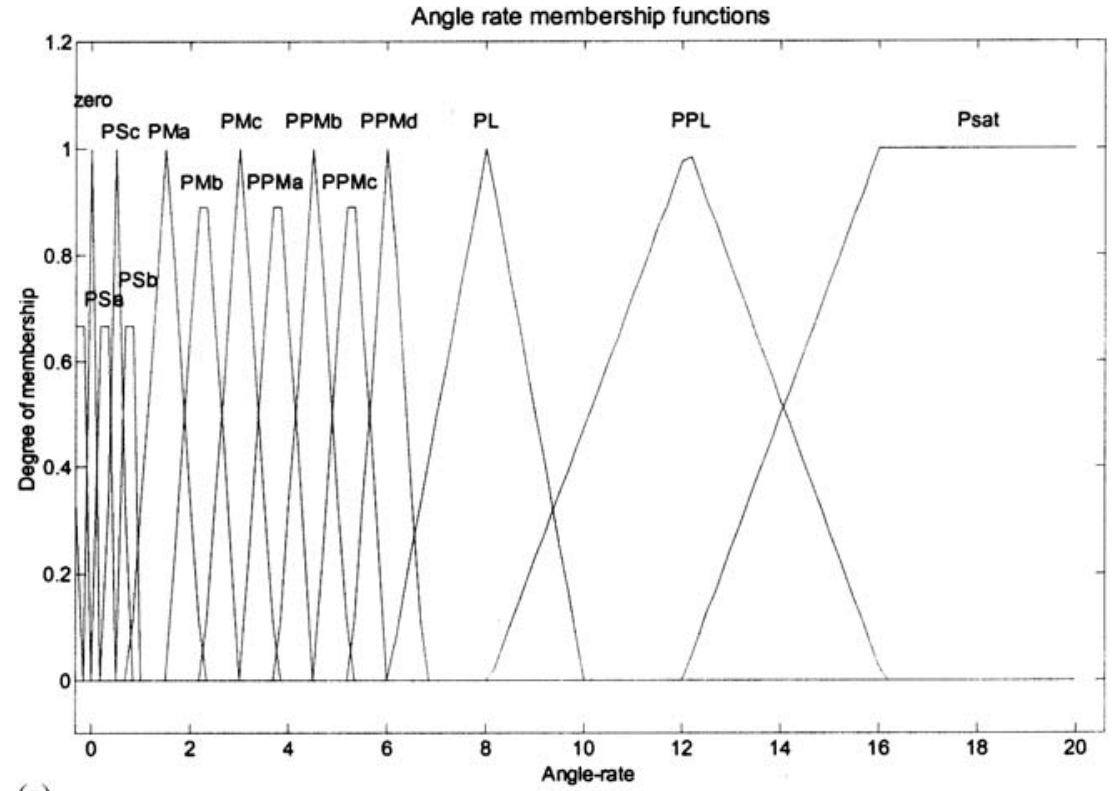

(c)

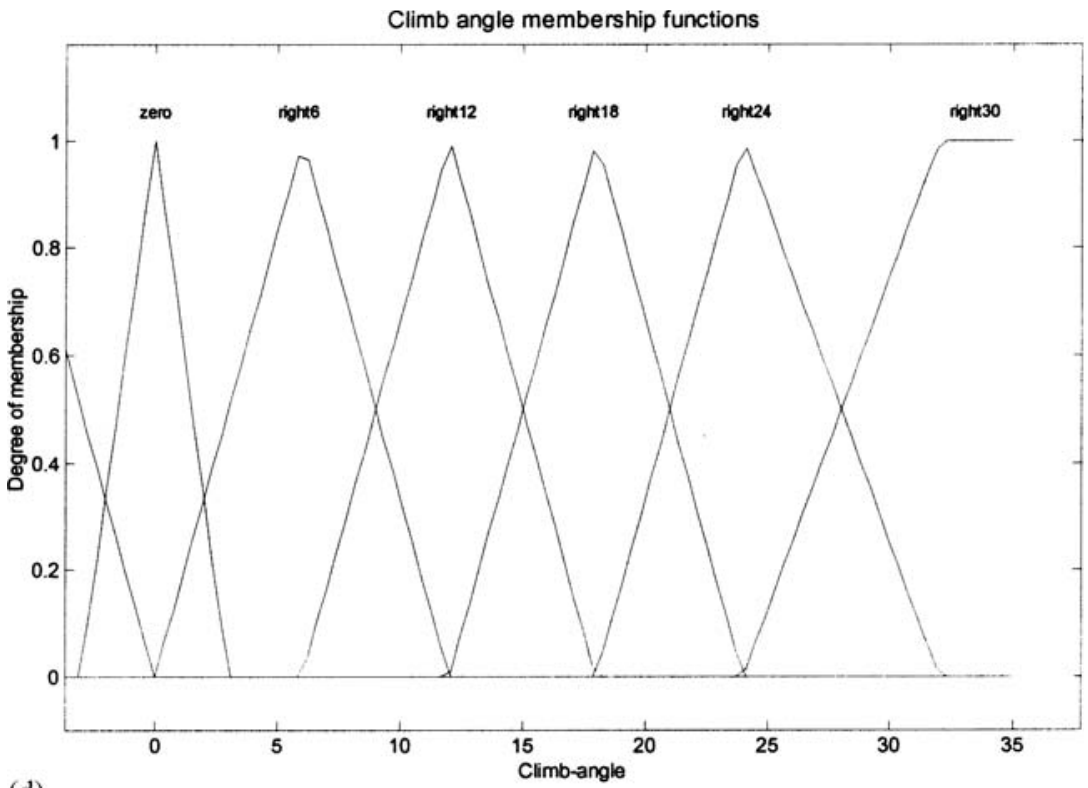

(d)

Fig. 7 (a) Input angle membership functions. (b) Speed difference membership functions. (c) Angle rate membership functions. (d) Measured climb angle membership functions

To obtain the vehicle motion and orientation within the pipe environment, optical speed encoders were attached to the wheels and a tilt sensor was fixed on to the chassis. The orientation of the vehicle is derived from the climbing angle, $\theta$. The time rate of change of climbing angle $(\mathrm{d} \theta / \mathrm{d} t)$ can be used by the fuzzy controller to determine when there has been a genuine demand input or whether the vehicle is merely drifting from the desired path.

Figure 12 shows tilt sensor data when the vehicle is driven horizontally in a straight pipe. Slight drift can be expected due to surface roughness or wheel slippage.
Here, the angular rate of change over time is very small. Figure 13 is the tilt sensor data of the vehicle in a $90^{\circ}$ bend. A low-pass filter was used to reduce tilt sensor noise due to oscillations of the internal sensing liquid. Figure 14 shows the angular rate of change. The first $8 \mathrm{~s}$ illustrate the vehicle at the entry level of the bend. This is followed by the vehicle climbing until it reaches the centre of the bend. The plateau region in the graph corresponds to when the vehicle is making the turn in the sharpest segment of the bend. The last few seconds display a negative rate of change, which indicates that the vehicle is being driven back to its original horizontal 


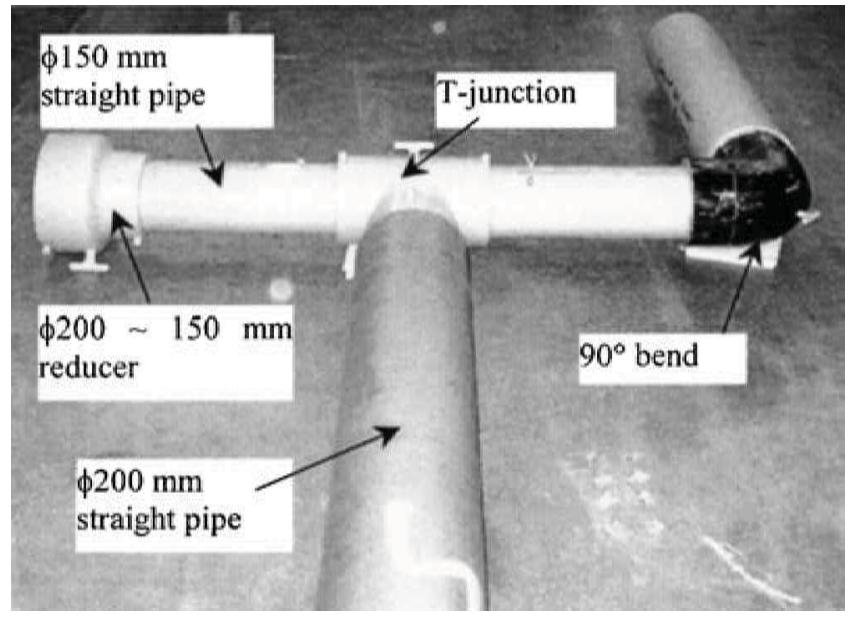

Fig. 8 Pipe arrangement

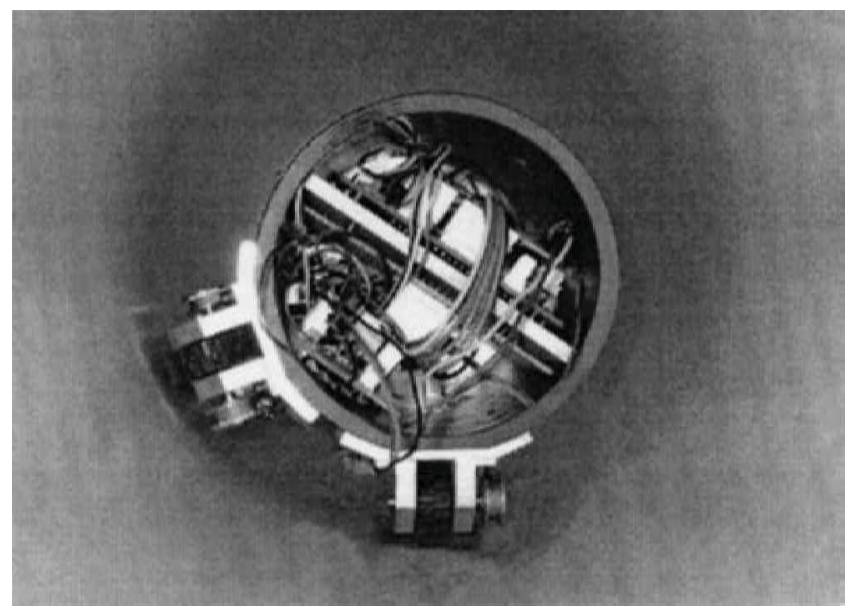

Fig. 9 The vehicle climbing in a straight pipe

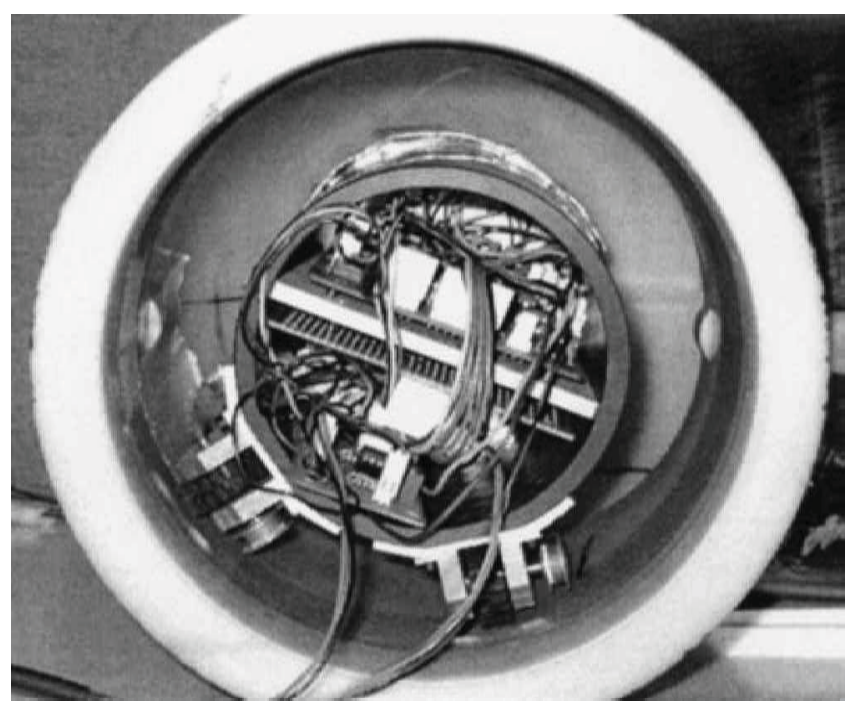

Fig. 10 The vehicle entering the elbow

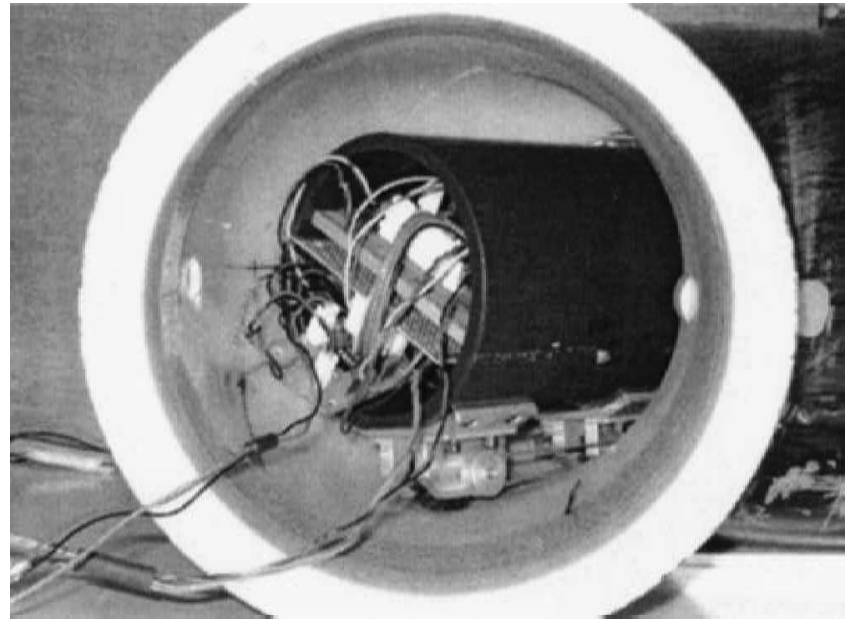

Fig. 11 The vehicle in the elbow

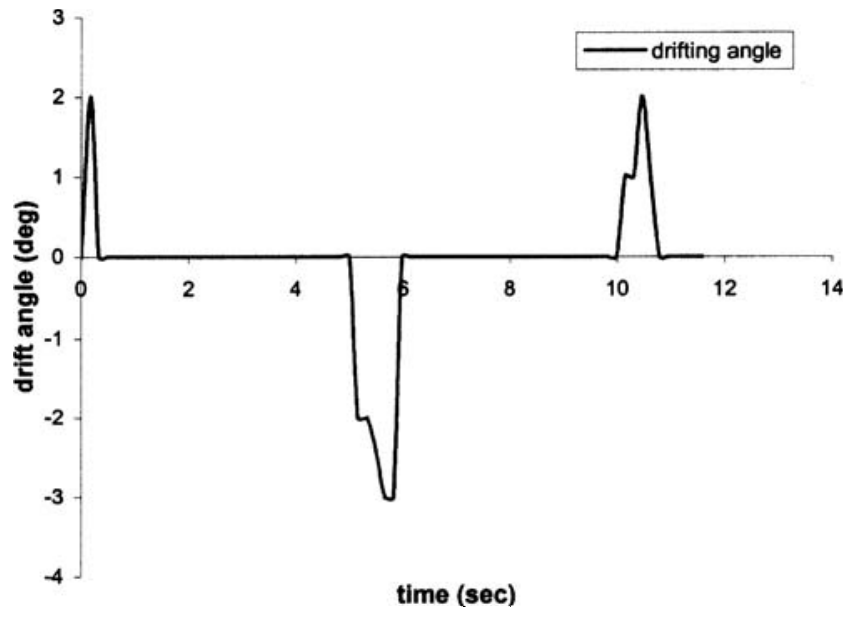

Fig. 12 Drifting of the vehicle unit in a straight pipe

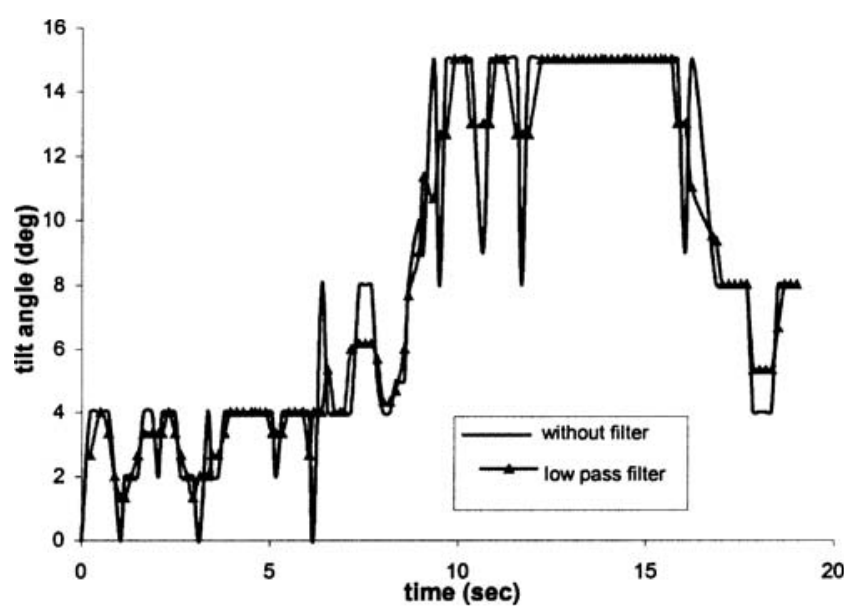

Fig. 13 Climbing angle profile of the vehicle unit in a bend

position. The fuzzy rules have been able to recognize the change and thus adjust the speed of the left and right sides accordingly.

Although the designed four-wheel vehicle configuration works well, its climbing angle is restricted to $30^{\circ}$. 


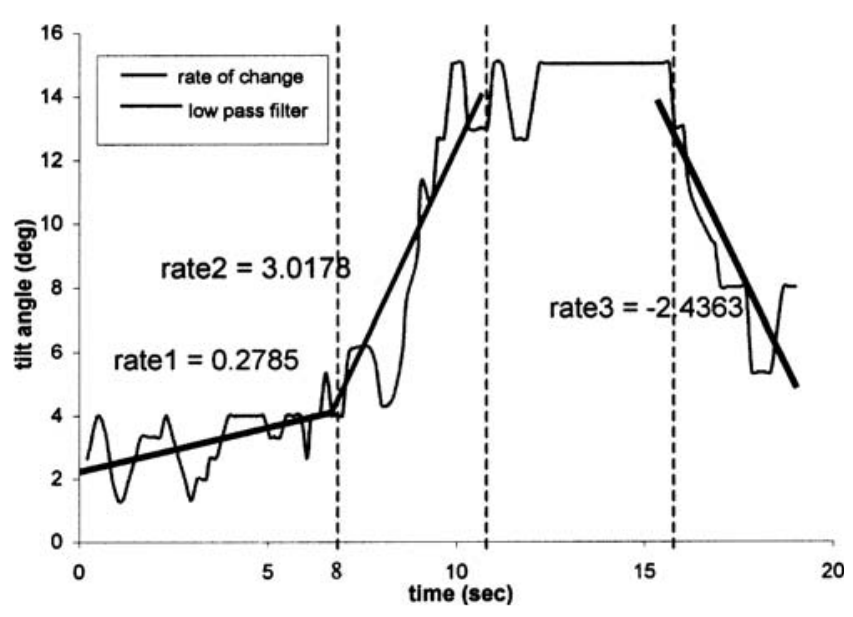

Fig. 14 The climbing angle rate change in a right-angled bend

Any angle larger than $30^{\circ}$ will cause the centre of gravity of the vehicle to move outside of the wheel base area and thus increase the risks of toppling over. Therefore, a third pair of passive wheels arranged in a triangular configuration will increase the stability. At the moment, the vehicle is powered and driven via a cable. Cable-less communication will be integrated into the robotic vehicle system and is discussed below.

\section{COMMUNICATIONS METHOD}

\subsection{Cable-less communications options}

The idea of a cable-less communication link between the vehicle and operator was included as a part of the robotic system concept. Such a link would be extended to intervehicle communication for cooperative multitasking applications. Conventional methods of remote vehicle communication have almost always used cables. However, there are several problems regarding this. Firstly, cable friction and drag tend to shorten operational distance. Secondly, extra payload is put on the vehicle. Thirdly, cable-handling problems include laying, collecting and possible cable break. The requirements for cable-less communication are the ability to transmit data and control signals, as well as to maintain consistent signal integrity and strength inside pipes. Bidirectional communication is needed among the vehicles as well as between the vehicle and operator. Several cable-free communication options used in the past include radio frequency (RF), acoustic waves and microwaves.

The choice of optical (laser) communication is based on an analysis of propagation issues [18, 19], especially transmission through the medium, background noise and ability to cope with a constrained pipe environment. $\mathrm{RF}$ is not considered due to interference with the pipe wall, particularly in cast iron sections, resulting in signal fading and echoes. RF has regulatory bandwidth and power, which limits its signal capacity and range.
Ultrasonic or acoustic methods are very dependent on the transmission medium. They may not be suitable in gas pipes where there are changes in the gas flowrate and pressure. In addition, they suffer from echoes and signal dispersion in a confined space. Microwave transmission efficiency is low, especially in metal pipes due to interference and energy absorption. Thus, more power at higher frequency is needed for transmission. Microwave or RF will induce current in the metal pipe, leading to power losses $\left(i^{2} R\right)$, and may also cause arcing.

An optical method, in particular laser, seems to be the correct option, as it possesses almost none of the major disadvantages of the above-mentioned communication methods. Laser light is highly stable, directional and has potentially a broad bandwidth, where a modulated beam is suitable for reliable data and video transmission. The enclosed transmission path in pipelines ensures minimum health and safety issues.

However, laser transmission is not without disadvantages. It is known that the signal will not travel around bends due to its line-of-sight characteristic. Other disadvantages are that of unfavourable pipe environment conditions, such as surface reflection, refraction and those that the gas content may introduce. The signal will be attenuated by both absorption and scattering processes. These arise from the presence of molecular constituents such as water vapour, whose concentration depends on many variables such as temperature and pressure. By using a high-power laser and error-correction techniques, these disadvantages can be minimized.

\subsection{Evaluation of the laser communications}

The aims of the experiments are to verify the feasibility of lasers for communication in pipelines and to discover their limitations. Major investigations have been focused on laser properties such as line of sight, reflections and focusing to ensure that these would not hinder its use in a pipe environment. The following were evaluated:

(a) laser transmitting distance in various environments, such as PE, cast iron, reflected from clean or dirty surfaces and around bends;

(b) verify distortion, scattering and divergence effects of the laser beam;

(c) possible noise sources and signal-to-noise ratio (SNR);

(d) surface reflectiveness due to different material, grease, dirt and water;

(e) the propagation distance and divergence angle of the laser beam before encountering reflections.

An InGaAs laser diode was used to generate a laser beam of $635 \mathrm{~nm}$ wavelength (visible red) [20]. The laser was operated in a constant power mode and was maintained at $10 \mathrm{~mW}$. A signal generator supplied a $2 \mathrm{~V}$ peakto-peak sinusoidal signal at $5 \mathrm{kHz}$ to modulate the laser.

Proc. Instn Mech. Engrs Vol. 217 Part I: J. Systems and Control Engineering 


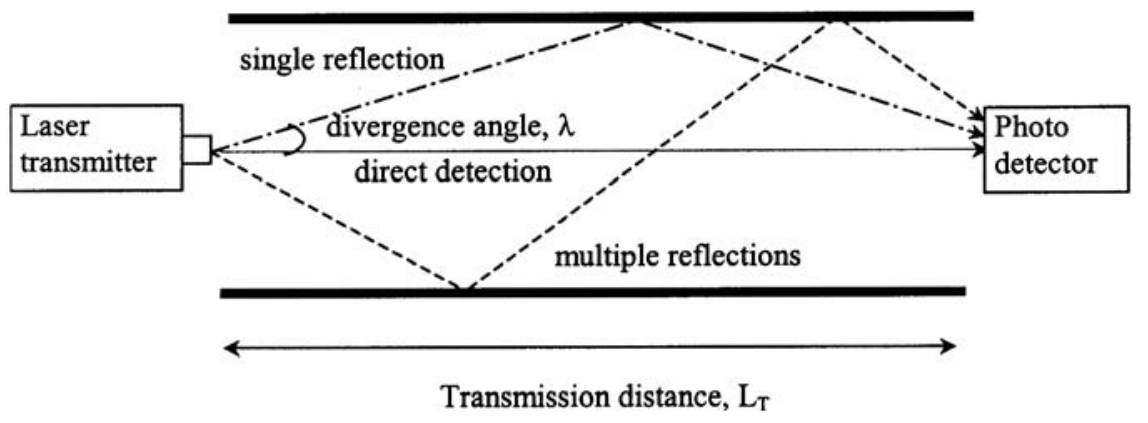

Fig. 15 Possible transmission paths

A silicon photodiode (PIN BPX65) was set up in reverse biased mode to detect the beam. Figure 15 illustrates possible paths of laser beam transmission, showing direct detection, single reflection and multiple reflections. Peakto-peak voltage, phase shift and the SNR were recorded.

The experiments were carried out in straight pipes as well as in a $90^{\circ}$ bend. The divergence characteristic of the semiconductor laser dictates that the beam diameter increases as transmission distance increases, which results in a decrease in laser intensity. The laser intensity is related to transmission distance according to the inverse square law and is of a Gaussian profile across its diameter. The transmission distance $L_{\mathrm{T}}$ can be estimated from the detection plane $A_{\mathrm{e}}$ using the following equation:

$$
A_{\mathrm{e}}=\pi \frac{\left(L_{\mathrm{T}} \theta_{\mathrm{D}}\right)^{2}}{4}
$$

Different divergence angles $\left(\theta_{\mathrm{D}}\right)$ were tested by adjusting the laser output focusing lens. The beam divergence was used to simulate a distance from the transmitter, due to the limited actual length of the test rig. Figure 16a shows that the divergence of the laser is not so severe, even at a $20 \mathrm{~m}$ projection distance, as to encounter reflections on the pipe walls. However, the transmission distance is largely affected by the signal strength and SNR, as in Fig. 16b. The detector SNR is proportional to the square of the received power. From the results obtained, the recommended communication distance is no more than $5 \mathrm{~m}$ for a $10 \mathrm{~mW}$ semiconductor laser. However, higher power lasers can safely be used to increase the distance, since the transmission path is enclosed and health and safety hazards are thus minimized to Class 1.

Phase change as the laser beam is reflected off the pipe surface was observed. This is an important observation as phase shift correction may be required for sending and receiving data, depending upon the modulation scheme to be adopted. Another important factor is the study of the laser transmission distance around bends ( 60 or $90^{\circ}$ bend). The transmitting distance would not be great for less than clear surfaces or consecutive bends. Another difficulty is the ambiguous reflection position on the bend surface that eventually changes the beam direction, therefore making detection difficult. The experiments showed that the detection is only possible for no more than $30 \mathrm{~cm}$ after reflection from an elbow surface in yellow PE pipe. Thus, the concept of using 'repeater' modules is suggested as a method of receiving a signal and re-transmitting it in another direction to achieve signal integrity and longer transmission paths around corners. This idea fits in well as part of the modular robotic system concept already developed.

From the experimental results, it was concluded that there are a few application rules. There is a need to impose maximum and minimum operational distances appropriate to transmitter output power and detector SNR. A minimum distance is required to ensure sufficient angular distribution to overlap the detector surface. Last but not least, it is recommended that surface reflections should be avoided in order to keep the signal processing efficient and simple without complex error correction algorithms. Directional control will be able to reduce path loss and multipath distortion.

\section{CONCLUSIONS}

A new robotic system for in-pipe services has been proposed. This paper proposed the use of a multirobotic vehicle system to remedy the limited ability of gas pipe inspection and repairing tools. Multirobotic systems have been widely developed for open-space usage, but are yet to be adopted in constrained and partially observable pipe environments. The work described demonstrates the effectiveness of integration of a simple mechanical design with various robotic technologies such as semi-autonomous control and cable-free communication.

The vehicle itself employs a simple, wheel-driven mechanism. It is able to provide mobility and flexibility to negotiate a typical low-pressure gas pipeline environment. The mobility relies mainly on the controller and sensor feedbacks. The robotic vehicle uses a PID controller together with fuzzy logic. The control strategy allows the robotic vehicle to navigate safely in gas pipelines and to detect and negotiate various types of bends and 
$10 \mathrm{~mW}$ laser diode: intensity vs distance, beam dia vs distance

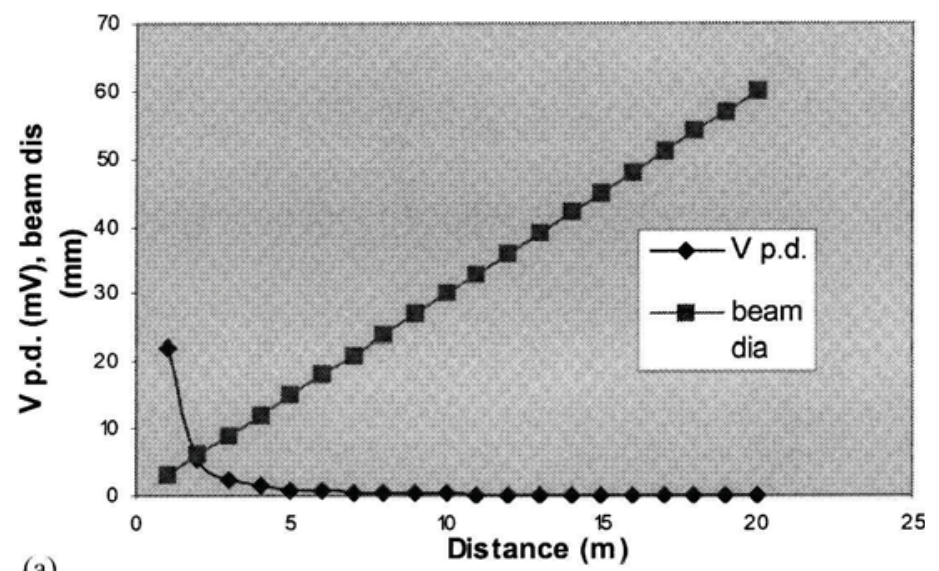

(a)

SNR (dB) vs distance $(m)$

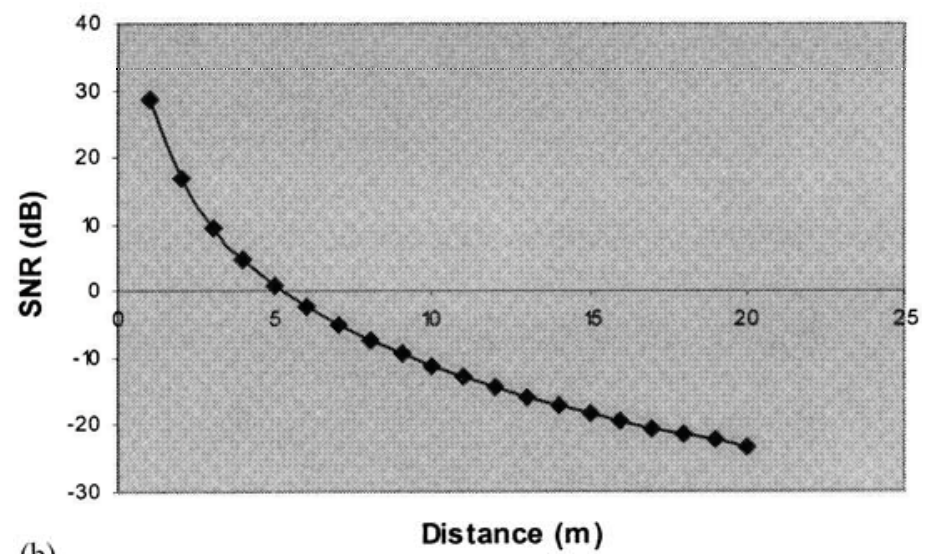

(b)

Fig. 16 (a) Operable distance for a $10 \mathrm{~mW}$ laser transmitter. (b) Signal-to-noise ratio in direct detection

fittings. The control algorithm developed uses an 'inputinterpret-act' control cycle by utilizing simple sensors such as the tilt sensor and optical speed encoders. The control strategy has been tested and proved to be robust and sufficient. With these features, operator intervention is minimized.

The research also shows that the application of in-pipe cable-free communication via laser is feasible. It will greatly extend the service distance compared to conventional tethered tools, which have problems due to cable drag and handling.

\section{REFERENCES}

1 Crouch, A. E., Bruton, F. A. and Bartlett, G. R. In-line inspection of unpiggable natural gas pipelines. GRI Topical Report GRI 95/0323, 1995.

2 Uzelaz, N. I. In-line inspection of gas transmission pipelines. Corrosion Prevention and Control, February 1995, 46(1), 3-12.

I05202 @ IMechE 2003
3 http://www.detv.gov.uk/housing/research/ehcs96/note5/ index.html, November 1999.

$4 \mathrm{http}: / /$ www.pipetech.com, January 2000.

5 MacConaill, P. A., Drews, P. and Robrock, K.-H. Mechatronics and Robotics, Vol. I, 1991 (IOS Press, The Netherlands).

6 Hollingum, J. Robots explore underground pipes. Ind. Robot, 1998, 25(5), 321-325.

7 Kawaguchi, Y., Yoshida, L., Kurumatani, H., Kikuta, T. and Yamada, T. Internal pipe inspection robot. In IEEE International Conference on Robotics and Automation, 1995 , pp. 857-862.

8 Zimmerman, H. J. Fuzzy Set Theory and Its Applications, 2nd edition, 1991 (Kluwer Academic, Dordrecht, The Netherlands).

9 McNulty, G. R. Use of PLS remote-controlled camera probes and PLS pipe crawling robots to examine live natural gas distribution. Proc. SPIE, 1995, 2454(185), 185-188.

10 Hertzberg, J., Christaller, T., Kirchner, F., Licht, U. and Rome, E. Sewer robotics. GMD - German National Research Center for Information Technology, 1997.

11 Hirose, S., Ohno, H., Mitsui, T. and Suyama, K. Design of in-pipe inspection vehicles for $25,50,150$ pipes. In

Proc. Instn Mech. Engrs Vol. 217 Part I: J. Systems and Control Engineering 
Proceedings of the 1999 IEEE International Conference on Robotics and Automation, May 1999, pp. 2309-2314.

12 Suzumori, K., Miyagawa, T. and Kimura, M. Micro inspection robot for 1-in pipes. IEEE/ASME Trans. Mechatronics, September 1999, 4(3), 286-291.

13 Cardarelli, G., Palumbo, M. and Pelagagge, P. M. Critical aspects in multi-robot co-operation. Ind. Robot, 1994, 21(5), 31-35.

14 Ong, J. K., Kerr, D. and Bouazza-Marouf, K. In-pipe multirobot system - modular configurable co-operative semiautonomous robotic units. In Proceedings of 2001 International Gas Research Conference, 2001.

15 Barshan, B. and Durrant-Whyte, H. F. Inertial navigation systems for mobile robots. IEEE Trans. Robotics and Automn, 1995, 11(3), 328-342.
16 Ruspini, E., Bonissone, P. and Pedrycz, W. Handbook of Fuzzy Computation, 1998, Ch. G6.1 (Oxford University Press).

17 Fuzzy Logic Toolbox User's Guide, Version 2, 2001 (The MathWorks Inc., Natick, Massachusetts).

18 Pratt, W. K. Laser Communication Systems, 1969 (John Wiley, New York).

19 Bloom, S., Chan, V., Arnold, R., Kremer, R. and Liu, C. S. Laser communications for UAV applications. Proc. SPIE, 1995, 2555, 85-95.

20 Kamran, S. Wavelength selection criteria for laser communications. Proc. SPIE, 1995, 2381, 342-357. 